\title{
The influence of cantilever length and implant angulation in completely edentulous patients using the finite element analysis and the All-on-four/Fast \& Fixed treatment concept - A review of the literature
}

\author{
Raluca-Gabriela Mocanu, Cristina Teodora Preoteasa, Daniela Meghea, \\ Elena Preoteasa, Laurentiu-Iulian Florica, Sebastian-Robert Mocanu \\ "Carol Davila" University of Medicine and Pharmacy, Bucharest, Romania
}

\begin{abstract}
Aim. The purpose of this literature review is to provide an overview of the finite element analyses on All-on-four and Fast \& Fixed treatment concept, regarding the dimension of the distal cantilever and the degree of implant tilting. Material and methods. An electronic search including major medical data bases as: PubMed (Medline), Google Academic, Semantic Scholar, Elsevier, Science Direct, Wiley Online Library. The following searching terms were used: finite element analysis, implant cantilever length, tilted implants.

Results. Eight articles were selected for this review. According to their results, a value between 30 and 45 degrees in angulation and a minimal cantilever length represents the best way to elaborate the final prosthetic restorations. Conclusion. The common opinion of all the research studies included is that whenever the implant angulation increases and the dimension of the cantilever decreases, the clinical outcomes will be favorable and predictable.
\end{abstract}

Keywords: cantilever length, implant, tilting, edentulous mandible, edentulous maxilla, marginal bone loss, immediate loading, fixed implant rehabilitation

\section{INTRODUCTION}

Dental implants for the rehabilitation of partial or complete edentulism it is nowadays a frequently used technique, made in order to overcome the negative aspects of the conventional restorations. Over the past years, research was driven by the never ending wish of clinicians to use fewer implants to reduce the difficulty of the surgery and to minimize the costs for the patients on the one hand, and on the other hand to avoid anatomical regions of the mandible and the maxilla. Such regions, especially the posterior part of the mandible and the maxilla suffer from severe bone loss and are located next to important anatomical landmarks such as the maxillary sinuses, the inferior alveolar canal and the mental foramen. In order to outcome this anatomi- cal limitations without the use of complex surgical techniques, it was developed the implant supported fixed rehabilitation using tilted distal implants and cantilever extension [1,2].

This concept was first described by Paulo Malo and coworkers in 2003. They used 4 implants placed in the completely edentulous mandible, two of which were placed axially and the other two, the distal ones were placed in an angled position meant to avoid anatomical limitations and at the same time to extend the length of the future restoration to maximum.

Rehabilitation of the atrophic completely edentulous arches was always a problem in the distal areas especially because of the nearby anatomical aspects as the maxillary sinuses, the mandibular canal or the mental loop. Therefore, the tilted im- 
plants came out with the solution to outcome this problem. Their main role was to avoid the maxillary sinuses and the mandibular canal and to extend as much as it can the length of the prosthetic rehabilitation for maximizing the occlusal function. By using tilted implants instead of parallel ones, the dimension of the distal cantilever is reduced and therefore the forces measured around the periimplant bone are modified.

The tilting of the distal implants allows the use of longer implants, increased primary stability and the possibility of maximizing the occlusal area due to the distal cantilever.

Since this procedure first appeared, research was conducted to demonstrate if this was a reliable way to treat completely edentulous patients and whether the tilting of the distal implants and the cantilever length would affect in time the bone level around the implants. Until now, literature regarding this technique relates a survival rate of over $90 \%$, and implant failures in this cases appear more frequently related to errors in prosthodontic treatment, inadequate stress distribution associated with poor oral hygiene.

The finite element analysis has been used in order to evaluate and to predict the biomechanical effects that different types of implants have on the surrounding bone and the implications of the local factors on the osseous apposition and resorption. It is a useful tool that can predict the effect of occlusal forces in the structure of the implants and the stress distribution in the contact area between the implants and the cortical and trabecular bone.

The purpose of this review is to provide an overview of the finite element analyses on All-on-four treatment concept, regarding the dimension of the distal cantilever and the degree of implant tilting.

\section{MATERIALS AND METHOD}

\section{Search strategy}

The electronic search included: PubMed (Medline), Google Academic, Semantic Scholar, Elsevier, Science Direct, Wiley Online Library. The review included articles with English written abstracts and was made using the following searching terms: finite element analysis, implant cantilever length, tilted implants. In addition, review articles and references from different studies were used to find relevant studies which fit the inclusion criteria.

\section{Selection criteria}

In order to select the studies we developed a series of inclusion and exclusion criteria. Titles and abstracts of all potentially relevant articles were included in the review.

\section{Inclusion criteria}

- Studies written in English or Romanian

- Studies that used the 3D Finite Element Analysis

- Articles about cantilevers of fixed implant prosthesis in complete edentulous patients

- Articles about cantilevers of long term restorations in All-on-four / Fast \& Fixed rehabilitated patients and other methods of rehabilitation that involve this concept

- Articles about cantilevers of fixed implant restorations made on tilted /non-tilted implants in completely edentulous patients

- Type of patients included: maxillary or mandibular completely edentulous patients

Exclusion criteria

- Articles about cantilevers of fixed partial prosthesis

- Articles about cantilevers of hybrid prosthesis

- Articles about cantilevers of acrylic fixed prosthesis

- Articles where methods are not described, or for which full text was not available,

- Articles in languages other than English or Romanian

After checking once more if the articles matched the inclusion criteria, a Microsoft Excel spreadsheet was made in order to gather all the data.

\section{RESULTS}

At a first search by using the keywords mentioned earlier we found a number of 28986 related articles on the databases mentioned. Citations were screened and duplicates were removed. According to the title and the abstract that best fit the subject of the review, a number of 35 publications were selected, out of which only 8 were included in the review.

For each of the 8 articles selected, we collected the following data: the year and the month when the article first appeared, the angulation of the implants, the number of implants used for the study, the cantilever lengths, the tests used for measuring 


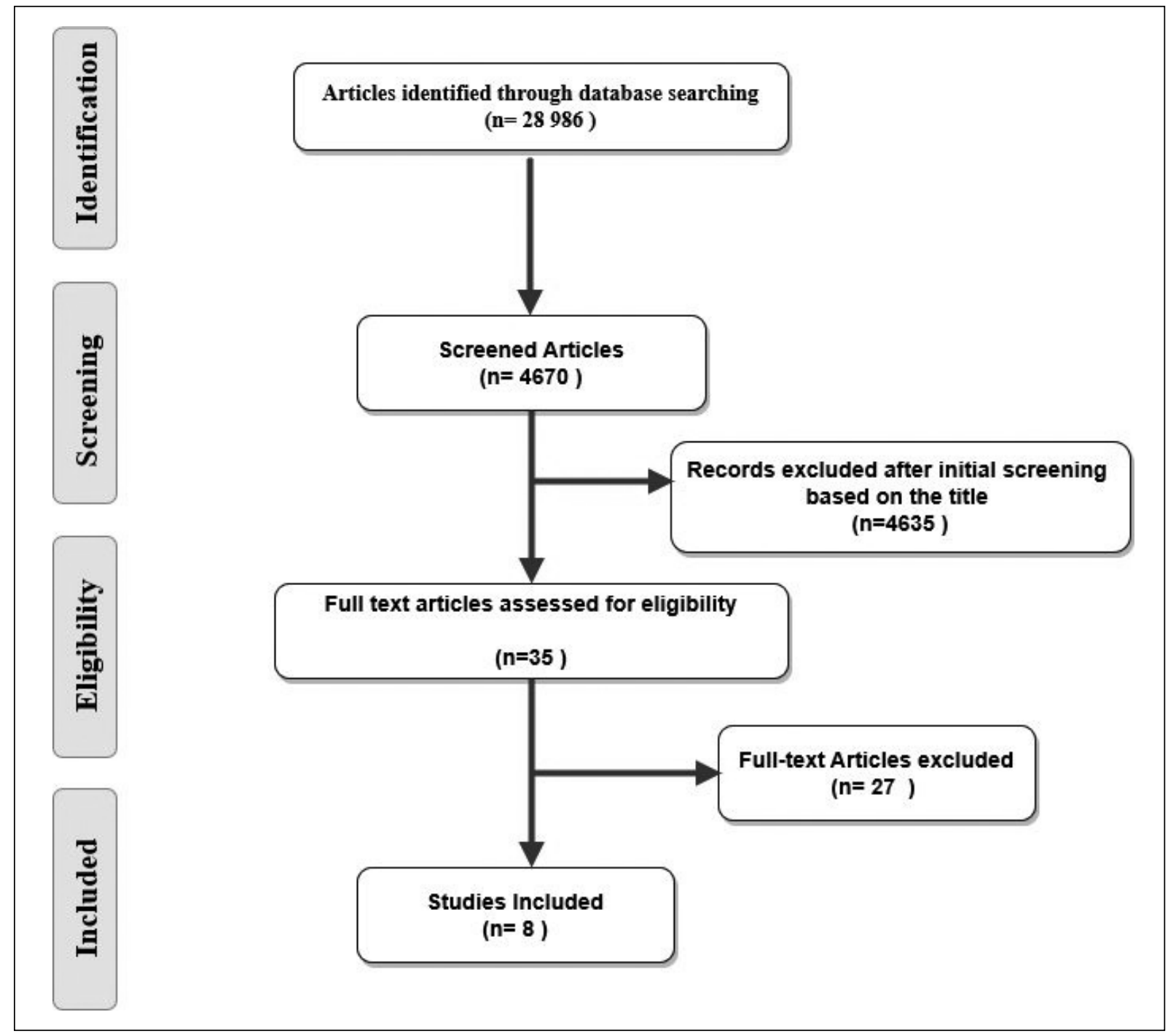

FIGURE 1. Procedural flow of the literature search and selection process

the effects of different cantilever lengths, the general conclusion of the study.

The studies included in the review were published from January 1993 until January 2018.

All studies included in this review were based on the 3D Finite Element Analysis by using differ- ent values for the tilting of the implants and for the dimension of the distal cantilever.

The finite element model used was either the maxilla or the mandible. The data extracted from the articles included the following parameters: number of implants, implant angulation, cantilever

TABLE 1. Included studies, their testing parameters and data obtained

\begin{tabular}{|c|c|c|c|c|c|}
\hline References & $\begin{array}{c}\text { No of } \\
\text { implants }\end{array}$ & $\begin{array}{c}\begin{array}{c}\text { Implant angulation } \\
\text { (degrees) }\end{array} \\
\end{array}$ & $\begin{array}{c}\text { Cantilever length } \\
(\mathrm{mm})\end{array}$ & Occlusal force & $\begin{array}{c}\text { Maxilla or } \\
\text { mandible }\end{array}$ \\
\hline Malhotra et al. 2012 [3] & 4 & $30 / 40$ & $4 / 12$ & $\begin{array}{l}100 \mathrm{~N} \text { on axial implants } \\
250 \mathrm{~N} \text { on tilted implants }\end{array}$ & Mandible \\
\hline Bevilacqua et al. 2008 [4] & 5 & $0 / 15 / 30 / 45$ & $15 / 11.6 / 8.3 / 5$ & $150 \mathrm{~N}$ & Mandible \\
\hline Bevilacqua et al. 2011[5] & 4 & $0 / 15 / 30 / 45$ & $13 / 9 / 5 / 0$ & $150 \mathrm{~N}$ & Maxilla \\
\hline Jacques et al. 2009 [6] & 5 & - & $10 / 15 / 20$ & $100 \mathrm{~N}$ & Mandible \\
\hline Geremia et al. 2009 [7] & 5 & - & $10 / 15 / 20$ & $50 N$ & Mandible \\
\hline Ozan et al. 2018 [8] & 4 & $0 / 17 / 30 / 45$ & $21.6 / 16.4 / 12.8 / 10$ & $100 \mathrm{~N}$ & Mandible \\
\hline Bellini et al. 2009 [9] & 4 & - & $5 / 15$ & - & Mandible \\
\hline Rodriguez et al. 1993 [10] & 6 & - & $7 / 14 / 20$ & $15 \mathrm{lb}$ & Mandible \\
\hline
\end{tabular}


length, occlusal force and tests used to evaluate the effects. The information was summarized in table 1. As an overall conclusion of the previous stated results, all the researches included in this review came to a general opinion in which whenever the angulation of the distal implants increases and the cantilever dimension decreases is where the best clinical and stable results will appear. In the previous table, all the values that are "Bold" marked represent the optimal values of the angulation and the cantilever dimension as shown by the research that each author conducted.

\section{DISCUSSION}

The overall opinion stated in each study included in the review, was that whenever the length of the cantilever increased and the implant inclination value approached the 0 degree value, the stress measured in the cortical bone, in the implant itself and in the structures of the prosthetic restoration increased no matter the intensity of the force applied. In most studies the force applied ranged from $100 \mathrm{Ncm}[3,6,8]$ to $150 \mathrm{Ncm}[4,5]$. The maximum force applied was $250 \mathrm{Ncm}$ in a study conducted by Malhotra et al. in 2012 [3]. He used the 3D Finite Element Analysis on an All-on-four model with distal implants tilted to 30 and 40 degrees and a cantilever length of 4 and $12 \mathrm{~mm}$. The maximum force of $250 \mathrm{Ncm}$ was applied to the distal extremity of the cantilever to simulate the forces recorded during mastication in the molar and premolar area. Also, axial forces were used to simulate the forces in centric relationship, and oblique ones (applied at an angle of 30 degrees) were used as biting forces. $\mathrm{He}$ considered that until the cantilever length doesn't reach a maximum value of $15 \mathrm{~mm}$, there are no significant changes in the pressure measured in the periimplant bone and in the implant. Value of masticatory force was chosen for the models because it is the most important oral function, with impact on oral health quality of life $[11,12]$. Even so this parameter registers variations according to factors as patients and food characteristics [13].

In spite of this previous mentioned publication that stated that there are no major differences until the $15 \mathrm{~mm}$ cantilever length is reached [3], the other publications came to completely different results [4-10]. Two of them [4,5] conducted by the same main author, Bevilacqua, took into consideration the same total length of the fixed prosthetic restauration and changed the implant angulation as following. For the 3D model used in 2011 the angulations were as following: 0 degrees angulation of implant and $15 \mathrm{~mm}$ the cantilever length, respectively 15degrees for $11.6 \mathrm{~mm}$, respectively $30 \mathrm{de}-$ grees for $8.3 \mathrm{~mm}$, and respectively 45 degrees for 5 $\mathrm{mm}$. In 2008 the angulations used for the tests were: 0 degrees while the cantilever length was 13 $\mathrm{mm}$, respectively 15 degrees for $9 \mathrm{~mm}$, respectively 30 degrees for $5 \mathrm{~mm}$, respectively 45 degrees for $0 \mathrm{~mm}$. In both studies $[4,5]$ the overall result was the same, that the mechanical stress is minimal when the length of the cantilever is minimal. The greatest stress value was recorded in the bone surrounding the axial implants. There were measured values as following: for the distal axial implant 75.0 Mpa, 35.0 Mpa for the mesial implant and 95.0 Mpa for the metallic structure of the prosthesis. The mechanical stress was also higher in the periimplant bone when loading and tilting single implants compared to the stresses observed around vertical implants.

In all studies the maximum values of the stress were recorded in the cervical area of the implant in the cortical bone. There were no significant values in the trabecular bone no matter the angulation of the implants.

Jacques et al. [6] took into consideration also the material from which the metal framework of the prosthesis was made. They used a Co-Cr framework and a Pd-Ag one, and came to the conclusion that the Co-Cr alloy framework suffered higher abutment deformations as the cantilever length increased.

One of the limitations of this review was the small number of articles and studies based on the 3D Finite Element Analysis regarding this subject. Another negative aspect was the fact that the majority of the studies included were dated between the years 2008-2011 which means that the information provided might not be up to date.

\section{CONCLUSIONS}

As an unanimously conclusion to all studies and publications included in this review, tilting of distal implants supporting minimal cantilever lengths, 
rigidly splinted in a fixed prosthesis, decreased stress in the periimplant bone and in the metal framework. The implant angulation and cantilever length are factors that need to be adequately planned, in order to ensure a good outcome of rehabilitation by All-on-four/Fast-and-Fixed treatment concept.

\section{REFERENCES}

1. Preoteasa E, Florica LI, Obadan F, Imre M, Preoteasa CT. Minimally Invasive Implant Treatment Alternatives for the Edentulous Patient - Fast \& Fixed and Implant Overdentures. In: Turkyilmaz I. Current Concepts in Dental Implantology, IntechOpen. 2015:77-103.

2. Preoteasa E, Imre M, Lerner H, Tancu AM, Preoteasa CT. Narrow Diameter and Mini Dental Implant Overdentures. In: Virdi M. Emerging Trends in Oral Health Sciences and Dentistry; 2015:241-264.

3. Malhotra AO, Padmanabhan TV, Mohamed K, Natarajan S, Elavia U. Load transfer in tilted implants with varying cantilever lengths in an all-on-four situation. Aust Dent J. 2012;57(4):440-445.

4. Bevilacqua M, Tealdo T, Pera F, et al. Three-dimensional finite element analysis of load transmission using different implant inclinations and cantilever lengths. Int J Prosthodont. 2008;21(6):539542.

5. Bevilacqua M, Tealdo T, Menini M, et al. The influence of cantilever length and implant inclination on stress distribution in maxillary implant-supported fixed dentures. J Prosthet Dent. 2011;105(1):5-13.

6. Jacques LB, Moura MS, Suedam V, Souza EA, Rubo JH. Effect of cantilever length and framework alloy on the stress distribution of mandibular-cantilevered implant-supported prostheses. Clin Oral Implants Res. 2009;20(7):737-741.

7. Geremia T, Michelon-Naconecy M, Mezzomo A, Cervieri A, Shinkai A, Sadami R. Effect of cantilever length and inclined implants on axial force and bending moment in implant-supported fixed prostheses. Rev Odonto Ciênc. 2009;24(2):145-50.

\section{Acknowledgment}

All authors have an equal contributions as the first author.

\author{
Conflict of interest: none declared \\ Financial support: none declared
}

8. Ozan O, Kurtulmus-Yilmaz S. Biomechanical Comparison of Different Implant Inclinations and Cantilever Lengths in All-on-4 Treatment Concept by Three-Dimensional Finite Element Analysis. Int J Oral Maxillofac Implants. 2018;33(1):64-71.

9. Bellini CM, Romeo D, Galbusera F, et al. Comparison of tilted versus nontilted implant-supported prosthetic designs for the restoration of the edentuous mandible: a biomechanical study. Int J Oral Maxillofac Implants. 2009;24(3):511-517.

10. Rodriguez AM, Aquilino SA, Lund PS, Ryther JS, Southard TE. Evaluation of strain at the terminal abutment site of a fixed mandibular implant prosthesis during cantilever loading. J Prosthodont. 1993;2(2):93-102.

11. Oncescu Moraru AM, Preoteasa CT, Wagner A, Murariu-Măgureanu C, Meghea D, Preoteasa E. Instrumente de măsurare a calităţii vieţii, în relaţie cu performanţele masticatorii, la pacienţii în vârstă protezaţi mobil. Romanian Journal of Stomatology. 2019;65(1):5-9.

12. Bicheru M, Preoteasa CT, Imre M, Preoteasa E. The impact of general and oral health status on removable dentures and quality of life among the elderly. A literature review. Romanian Journal of Stomatology. 2018;64(4):215-221.

13. Oncescu Moraru AM, Preoteasa CT, Preoteasa E. Masticatory function parameters in patients with removable dental prosthesis. J Med Life. 2019;12(1):43-48. 